\title{
A critique of using age to ration health care
}

\author{
Roger W Hunt Southern Community Hospice Programme, South Australia
}

\section{Author's abstract}

Daniel Callahan has argued that economic and social benefits would result from a policy of withholding medical treatments which prolong life in persons over a certain age. He claims 'the real goal of medicine' is to conquer death and prolong life with the use of technology, regardless of the age and quality of life of the patient, and this has been responsible for the escalation of health care expenditure.

Callahan's proposal is based on economic rationalism but there is little evidence to suggest that substantial economic savings could be achieved. Moreover, his argument raises serious moral objections. A policy of withholding treatments from members of a social group involves elements of compulsion and discrimination, both of which would intrude on the doctor-patient relationship, undermine the autonomy of elderly patients, and invoke the slippery slope towards involuntary forms of euthanasia. Life-death decisions should be based on more than the one criterion of age, and take account of more relevant factors such as the patient's usual state of well-being, her/his expressed wishes, informed consent and the type of illness. Any move to the implementation and enforcement of the policy Callahan recommends would be rejected by health professionals and the public.

\section{Introduction}

Daniel Callahan, Director of the Hastings Center, has written Setting Limits, a book about the allocation of medical resources and the management of decline and death (1). As background Callahan identifies spiralling health care costs, portrays the role of medicine in the demographic transition, and claims biotechnology is used to extend life regardless of the quality of life of patients. His argument traverses economic, political, social, moral and medical spheres to the conclusion that life-extending treatment for the elderly should be curtailed after a certain age is reached. Other philosophers and medical ethicists have similarly recommended the use of age

\section{Key words}

Aged care; resource allocation; medical ethics; euthanasia. to ration medical resources $(2,3)$. Debate about this issue will not readily disappear from the agenda of policy-makers in developed countries where economic rationalism is applied to health care systems which are required to treat an increasingly aged population.

In this critique I will challenge Callahan's position on three grounds. Firstly, he creates flawed premises; his portrayal of contemporary approaches to decline and death is narrow, emphasising the biotechnological paradigm of medical care, the power of which he inflates. Secondly, there are important moral criticisms of his position. Thirdly, the doctor-patient relationship and clinical decision-making would be adversely affected by Callahan's proposal.

\section{Flawed premises}

With regard to 'the real goal of medicine', Callahan states, 'my guess is that by its unstinting effort to conquer the cause of death, its implicit agenda is a kind of prolongevity' (4). He claims that medical advancements have been responsible for 'the conquest of most infectious diseases and the great reduction in infant mortality' (5), that 'the health that science can conceivably make available is unlimited in scope' (6), and that 'technological advances of recent decades have been heavily responsible for the increase in life expectancy' (7). He further claims that if technology is available it will be used; 'both patients and families are likely to have the same inclination as the physician to treat ... it remains medicine's best, if not only, hope' (8).

Callahan's view of medicine emphasises the biotechnological paradigm of care, and neglects important areas of medicine which are not technology-intensive, such as psychiatry and preventive medicine, and those which aim to optimise quality rather than quantity of life, such as palliative medicine. Callahan clearly overestimates the power of biotechnological medical practice to extend human life. The dramatic decline in overall mortality in developed countries over the last century cannot be explained by the introduction of effective biotechnologies alone, since many of these were introduced several decades after a marked decline in mortality 
had already occurred. McKinlay and McKinlay cite diseases that, in their view, did benefit from medical intervention, and they claim that even if all of the decline in these diseases were attributable to medical measures including immunisation programmes, at best they account for only 3.5 per cent of the total decline in mortality (9). In assessing these statistics, Mckeown has argued that most of the decline in mortality since the second half of the 19th century was primarily due to improvements in hygiene and to rising standards of living, especially improved nutrition (10). More recently, the decline in the mortality rate of ischaemic heart disease since the mid-1960s has been attributed mainly to lifestyle changes, rather than to biotechnological advancement $(11,12)$, and Bailar and Smith have indicated that the massive biotechnological efforts to decrease the mortality rate of cancer have failed, and they argue that the main emphasis in the battle against cancer should shift from the search for a cure to prevention since many cancers are preventable (13).

Callahan's view that decisions to use biotechnology have so far ignored considerations of age cannot be supported by the literature. For example, observations have been reported from many countries, including America, which reveal that cancer is diagnosed at a more advanced stage in eiderly patients (14), and is less likely to be treated actively with chemotherapy, radiotherapy and surgery than in younger patients (15-17). Also in comparison to younger patients, older cancer patients are less likely to receive their terminal care in an acute care hospital, and are more likely to die in a less intensive setting, such as a nursing home $(18,19)$. The alternative of palliative care has been shown in a number of cost-comparative studies to be no less expensive than 'conventional care': hospice or palliative care, although not technology-intensive, is labour-intensive $(20,21)$. Analyses of patterns of hospitalisation and the use of medical technology by the aged suggest only small savings could be achieved with Callahan's recommendation (22). Levinsky has commented that 'only if routine medical care were withheld would the savings be substantial' (23).

With regard to social attitudes Callahan states there is an 'almost complete inability to find a meaningful place in public discourse for suffering and decline in life. They are recognised only as enemies to be fought .... We have created a way of life that can only leave serious questions of limits, finitude, the proper ends of human life, of evil and suffering, in the realm of the private or of religion ... banished to the closed confines of church or synagogue' (24). Yet over the last thirty years a body of salutory works has been produced, such as KublerRoss's famous book On Death and Dying, launched in 1969 when the 'death with dignity' movement was gathering momentum. The literature is now burgeoning with reports in the disciplines of medical ethics, gerontology, thanatology, palliative medicine and hospice care. Hospice care, which has emerged partly as a consequence of the failure of biotechnological medicine to meet the needs of dying patients and their families, directs energy towards coping and comforting, rather than towards denial of problems, and according to American social analyst Leonora Finn Paradis, has provided role models, social symbols and language that can be used for openly communicating feelings, beliefs, and attitudes about death (25).

Callahan's inaccurate caricature of medicine and misrepresentation of contemporary approaches to decline and death creates false premises, which therefore weakens his position. Nevertheless it is instructive to reflect upon the way Callahan develops his argument.

\section{Framework and assumptions of the argument}

Callahan assumes an essentially collectivistic or utilitarian perspective: 'The place of the elderly in a good society is an inherently communal, not individual, question (24) . . . Individualism should, in sum, give way to a community-based and affirmed notion of the value of the aged in society and, with that, an acceptance of limits to health care for the aged' (26).

A longstanding debate exists in philosophical and sociological literature about individualism and collectivism. Collectivistic assumptions can be helpful for the analysis of many public health issues, since many social terms cannot be readily defined or conceptually analysed and explicated in individualistic terms (ie terms standing for individual persons, or the properties and relations which individuals qua individuals might possess). Questions of ontological priority are raised by Callahan's assumptions: Are individuals somehow ontologically prior to (or more basic than) societies, or are societies ontologically prior to individuals? The latter is implicit in Callahan's vision, yet it can be argued that individuals are ontologically prior to societies, that individuals $q u a$ individuals might exist outside of society, but that societies could not exist at all without there being individual people qua individuals. Individuals are in this sense the ultimate constituents of societies. Ethical principles relating to the interactions of individuals certainly deserve more attention than Callahan ascribes. The principle of autonomy, in particular, barely rates a mention in Setting Limits. But such a prima facie moral principle is, from the point of view of an individual agent, a logical condition for the satisfaction of one's own interests, and also articulates modes of treating other people as ends in their own right rather than as a means to one's own ends.

The curtailment of the autonomy of the aged is justified by Callahan, firstly because of supposed 
economic savings, the benefits of which could be distributed elsewhere, and secondly because the aged could find greater meaning in their lives through an enhanced acceptance of a 'natural lifespan'. Neither reason can be accepted. The first, not only because significant savings are unlikely, a point I have already made, but also because of moral objections.

The moral paradigm for Callahan's argument is utilitarianism, particularly in its consideration of an 'aggregated good'. The utilitarian calculation aims at the maximisation of good, and to this end Callahan discusses the inter-generational transfer of resources. As is prone to occur with a utilitarian framework however, substantive difficulties arise in defining an agreeable set of factors for the equation, assigning weights to relevant factors, and identifying outcomes. Callahan's equation is inadequate in its economic, social and cultural analyses, and lacks considerations of justice.

The deontological-type criticism of Callahan's position is that he regards elderly people as the means to a greater social good, rather than as ends in their own right. He ignores the interests and claims of elderly individuals, suggesting they should be sacrificed for the benefit of others. The Kantian constraint on moral theory, a premise I accept, is that individuals do matter in their own right, and it is therefore unjust to sacrifice persons, simply because they are aged (or for that matter black or adherents to certain religious beliefs etc), with a view to some supposed overall utility.

Given a desire to distribute health care resources justly, and a deontological constraint that individuals matter in their own right, I propose to argue that an egalitarian theory best realises distributive justice. Other theories of distributive justice, such as those of merit (what is deserved), libertarianism (according to choice), Rawls (equality plus the difference principle) and Walzer (pluralist theories of justice), seem less likely to realise the deontological constraint. Using egalitarian theory, distributive justice requires rationing, not for some 'aggregated good' however, but rather for the evening out of well-being according to individual needs and interests. In this sense, individuals should be regarded as ends in their own right, independently of everyone else, and should be treated according to the equal satisfaction of their needs and interests.

It is clearly in each individual's interest to have his or her autonomy respected. This is an important part of human well-being, and should apply equally to individuals regardless of age. To identify a group of people in society and to accord less value to their judgements, is discriminatory. Callahan's proposal negatively discriminates against the aged, yet, incredibly, he has argued it will benefit the aged by producing a more cohesive society. Ironically, Callahan aspires to improving the lot of the aged while his position is more aligned to the 'ageism' he condemns. If the aged are to be valued members of society, with their wisdom acknowledged, then their scope for negotiating the type of medical treatment they receive should not be restricted relative to other members of society.

A reason for Callahan's justification of his policy proposal is that by setting an age limit, decline and death can be perceived as more natural, and not to be avoided at all cost, but, in reality, death and decline are not avoided at all cost by either patients or doctors. As previously observed, elderly people are already less likely to have life-extending treatments than younger persons. This means that age could be a differentiating factor in clinical negotiations about life-extending medical treatments. That is, given equal levels of autonomy and an equal range of treatment options an elderly person may be less likely than a young person to undertake lifeextending treatments. It does not follow, however, that if some elderly people tend to forego lifeextending treatments, then all elderly people should be encouraged to do the same, and less so that these treatments should be compulsorily withheld from all persons once they have reached a certain age. I propose that the egalitarian principle should apply to discrete decision-making about life-extending treatments, with the distribution of autonomy and resources aimed towards the equal satisfaction of individual interests.

Curiously, Callahan condones compulsory passive euthanasia but rejects voluntary active euthanasia; 'a sanctioning of mercy killing and assisted suicide for the elderly would offer them little practical help and would serve as a threatening symbol of devaluation of old age .... it would convey precisely the wrong symbolism' (27). His position in relation to the various categories of euthanasia can be summarised in tabular form (Figure 1):

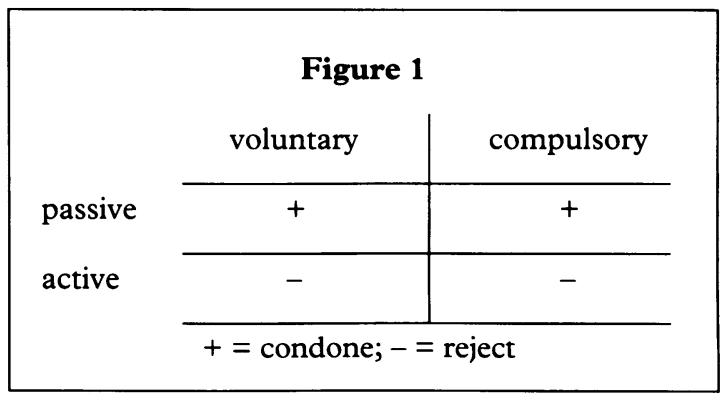

In thinking about the 'slippery slope' towards the universally denounced category of involuntary active euthanasia, it is relevant to assess the ability to distinguish between active/passive and voluntary/involuntary. Through my clinical work as a palliative care practitioner I am aware that the line between passive and active can easily become blurred. Vigorous symptom control measures when used to palliate suffering can frequently accelerate the process of 
dying. If a passive-active continuum is coupled with an acceptance of compulsion, if involuntary acts are condoned as suggested by Callahan, then an ominous potential to slide is created. On the other hand, protection can be afforded by maintaining a distinction along the voluntary/involuntary dimension. When compulsion is rejected, and a clear respect of the principles of autonomy and consent instituted, then there exists a strong safeguard against involuntary/compulsory active euthanasia.

\section{Clinical decision-making}

Callahan argues that age is 'the equivalent of such typical medical indicators as weight, blood pressure, or white-cell count'. He also argues that 'Just as those characteristics would be reasonable considerations in treating a patient so also would age' (28), that age is the final common indicator of a number of considerations, and that 'a full biography, even if more details are still to be added ... would normally be expected by the late 70 s or early 80 s' $^{\prime}(29)$. A full biography, however, varies enormously between individuals. Age at best can be considered a very crude prognostic indicator which has been associated with factors such as sex and socioeconomic status. Callahan did not state why he chose age as his indicator instead of wrinkles or grey hair, both of which could also correlate with 'natural life-span', and he gave no indication as to whether or not he thought the age limit for females should be set seven years higher than for males, in line with current gender-specific life-expectancies. Also, Callahan did not defend a scenario in which the age limit could be progressively reduced because of budget blow-outs and tighter fiscal policies.

Even if age is considered to be a typical medical indicator, it would be extraordinary to base a life and death decision on any one medical indicator. Chronology indicates virtually nought about other more important clinical considerations, such as the patient's quality of life, the amenability of a condition to treatment and the expressed wishes of the patient and family. It would be unrealistic and simplistic to ascribe age absolute pre-eminence in all life-death clinical decision-making relating to elderly persons. One can imagine myriad ways doctors and patients could find to challenge such a prohibitionary ruling.

Callahan's representation of the patient-doctor relationship is partial. He depicts the doctor as a monotherapeutic agent, whose business it is to extend life, and the patient as hopelessly submissive to paternalistic medical managers. I don't claim that doctor-patient communication or their relationship is ideal, and I don't reject outright the idea of external social forces being brought to bear on clinical decision-making, but I do argue that Callahan has broached this issue with little understanding or sympathy for the process of negotiation in the clinical setting, and that his proposal is devoid of any constructive incentive for improving the quality of the doctor-patient interaction.

\section{Conclusion}

Callahan's portrayal of contemporary medical care is narrow and outdated, as is his conception of the way in which decline and death are perceived in modern society. His conclusion cannot be justified because of false premises. Additionally, however, there are serious flaws with the construction of his argument. His collectivistic polarisation draws questions about ontological priority and criticism about the neglect of individualistic concerns, especially the discriminatory brutalisation of autonomy. The utilitarian position - withhold treatment of the aged for an overall good - treats aged persons as means to an end rather than as ends in themselves. The aspect of compulsion invokes the 'slippery slope' to involuntary forms of euthanasia, and the imposition of a stern state chaperone in the doctor-patient relationship, conjures images of totalitarianism. The use of chronology as the sole, overriding determinant in life-death clinical decisions is a forbidding proposal. Serious acceptance and enforcement difficulties would accompany any attempt to establish this recommendation as public policy.

\section{Acknowledgement}

My thanks go to Drs Rodney Allen, Brian Stoffell, Ian Maddocks and Neville Hicks for their consideration and advice regarding this paper.

Roger W Hunt, BM, BS, is Medical Co-ordinator of the Southern Community Hospice Programme, Flinders Medical Centre, Repatriation General Hospital, South Australia.

\section{References}

(1) Callahan D. Setting limits: medical goals in an aging society. New York: Simon and Schuster, 1987.

(2) Daniels N. Am I my parents' keeper? An essay on justice between the young and the old. New York: Oxford University Press, 1988.

(3) Veatch R M. Justice and the economics of terminal illness. Hastings Center report 1988; 18, 4:34-40.

(4) See reference (1):74.

(5) See reference (1):55

(6) See reference (1):109.

(7) See reference (1):142.

(8) See reference (1): 162

(9) McKinlay J B, McKinlay S M. The questionable contribution of medical measures to the decline of mortality in the United States in the twentieth century. Health and society 1977; Summer: 405-428.

(10) McKeown T. The role of medicine: dream, mirage or nemesis. London: Nuffield Provincial Hospitals Trust, 1976. 
(11) Syme S L. Social determinants of health and disease. In: Last J M, ed. Public health and preventive medicine (12th ed.): Norwalk, Connecticut: AppletonCentury-Crofts, 1986.

(12) Better Health Commission. Looking forward to better health. Canberra, 1986.

(13) Bailar J C, Smith E M. Progress against cancer? New England journal of medicine 1986; 314:1226-1232.

(14) Mor V, Masterson-Allen S, Goldberg R et al. Relationship between age at diagnosis and treatments received by cancer patients. Fournal of the American Geriatric Society 1985; 33, 9: 585-589.

(15) Samet J, Hunt W, Key C et al. Choice of cancer therapy varies with age of patient. Fournal of the American Medical Association 1986; 225, 24 : 3385-3390.

(16) Greenfield S, Blanco D, Elashoff R, Ganz P. Patterns of care related to age of breast cancer patients. Fournal of the American Medical Association 1987; 257, 20: 2766-2770.

(17) Greenberg E R, Chute C G, Stuket T et al. Social and economic factors in the choice of lung cancer treatment: A population-based study in two rural states. New England journal of medicine 1988; 318: 612-617.

(18) Roder D, Hunt R, Bonett A, Beare M. Where patients with cancer die in South Australia. Medical journal of Australia 1984; 141: 147-150.

(19) Hunt R, Roder D, McHarper T. The impact of hospice services on place of death of South Australians. Cancer forum 1989; 13, 3: 110-113.

(20) MacAdam D, Boldy D, Gray D. A comparative cost analysis of terminal cancer care: a study of expenditure on health care during the last 90 days of life under a home-based hospice service and in hospital. Cancer Foundation of Western Australia, 1985.

(21) Greer D S, Mor V, Morris J et al. An alternative in terminal care: results of the National Hospice Study. fournal of chronic diseases 1986; 39, 1: 9-26.

(22) Danis M, Patrick D L, Southerland L I, Green M L. Patients' and families' preferences for medical intensive care. fournal of the American Medical Association 1988; 260: 787-802.

(23) Levinsky N G. Age as a criterion for rationing health care. New England journal of medicine 1990; 322, 25 : 1813-1816.

(24) See reference (1): 32.

(25) Paradis L. Hospice handbook. Rockville, Maryland: Aspen Publications, 1985: 8-9.

(26) See reference (1): 60.

(27) See reference (1): 194-197.

(28) See reference (1): 164.

(29) See reference (1): 172. 